\title{
Study on the Influence of Moisture Content and Drying-Wetting Cycles on the Shear Strength Index of Silt in the West Bank of Qinghai Lake
}

\author{
Lei Zhang $(\mathbb{D}$, Jixiang Yan, Jiake Tan, and Yi Liao \\ Faculty of Civil Engineering and Mechanics, Kunming University of Science and Technology, Kunming 650500, China \\ Correspondence should be addressed to Lei Zhang; zl5359@163.com
}

Received 20 July 2021; Revised 7 September 2021; Accepted 29 September 2021; Published 14 October 2021

Academic Editor: Zhi Cheng Tang

Copyright ( 92021 Lei Zhang et al. This is an open access article distributed under the Creative Commons Attribution License, which permits unrestricted use, distribution, and reproduction in any medium, provided the original work is properly cited.

\begin{abstract}
In this paper, the expressway engineering case along the west bank of Qinghai Lake is taken as the research background, and the typical "aquatic grassland" silt on the west bank of Qinghai Lake is taken as the research object. Through the geotechnical test, wet-dry cycle test, and direct shear test, the influence of moisture content and wet-dry cycle on the shear strength of silt and its indexes are studied. The results show that the shear strength index $c$ and $\varphi$ of unmodified silt first increase and then decline with the increase of water content, and the optimal moisture content of the shear strength is about $30 \%$. The values of $c$, $\varphi$, and shear strength of remolded silt decrease with the increase of wetting and drying cycles. When the cycles exceed 5 times, the moisture content does not have much effect on the shearing strength.
\end{abstract}

\section{Introduction}

As an important facility to promote the development of regional economy, tourism, transportation, and other industries and people's livelihood, the construction of the expressway is particularly important. In order to take into account the geographical location and the need for construction technology, many important expressways and railway projects are built on shaky foundation soil. Taking the expressway project around Qinghai Lake as an example, the subgrade of the highway must be built on the "water meadow" with low bearing capacity and high compressibility. However, the subgrade of expressway constructed on deep soft soil will have significant deformation problems, which will not only affect the stability of the foundation but also affect the safe passage of vehicles in severe cases.

Domestic and foreign scholars have considered the influence of water content and dry-wet cycle on various rocks and soils. For example, Peng et al. [1], Raymond and Huang [2], Hua and Yin [3, 4], Zhou et al. [5], Li et al. [6], and Huang et al. [7] successively studied the influence of water content on cohesion $C$, internal friction angle, and strength of soil by different experimental means. Liu et al. [8], Tang et al. [9], Du et al. [10], Deng et al. [11-13], Liu et al. [14], Jiang et al. [15], and $\mathrm{Wu}$ et al. [16] studied Yunnan laterite and TGR Region (Three Gorges Reservoir Region) by various methods such as triaxial tests and direct shear tests. A large number of studies show that moisture content and drying-wetting cycles have great influence on the main mechanical indexes and strength of rock and soil, which will lead to the deterioration of mechanical indexes and the decrease of strength of rock and soil. Yao et al. [17], based on granite, studied the influence of stress on the soil water retention curve of unsaturated soil and the prediction of land subsidence. Zhang et al. [18-20] studied the resilient behavior of pavement subgrade under freeze-thaw cycles, cyclic load tests of saturated subgrade soil, and soil water characteristic curve of unsaturated clay embankment in southern China and put forward relevant theories.

Based on numerous studies, this paper, taking the typical silt layer of "aquatic grassland" on the west bank of Qinghai Lake as the research object, analyzes, and studies the shear strength and indicators of the silt layer of "aquatic grassland" 
affected by the change of water content and the effects of wet and dry cycles through experimental methods.

\section{Project Profile}

In recent years, with the construction of China's "the belt and road initiative," the construction of various critical infrastructures in the western region has flourished.

The average elevation of Qinghai Lake Basin is 3000 meters, which belongs to the subarid climate. The annual average temperature is about $1.5^{\circ} \mathrm{C}$, annual sunshine hours are about 2,980 hours, the annual precipitation is about $400 \mathrm{~mm}$, and the annual evaporation is about $1581.75 \mathrm{~mm}$, forming a seasonal climate condition of drying-wetting cycles. Moreover, there is a large area of continuously developed aquatic grassland in the West Sea area of Qinghai Lake Basin, which is mainly composed of silt and silty clay, including loose-slightly dense breccia and humus. This aquatic grassland belongs to typical regional bad soft soil. The formation of aquatic grassland originated from the vicinity of Qinghai Lake, with the development of spring water on the hillside and poor surface drainage in some areas, leading to long-term water accumulation. Moreover, this complex environmental condition with abundant groundwater, the local accumulated water, and dryingwetting cycle climate will affect the geotechnical characteristics of aquatic plants in varying degrees. However, the author summarizes the existing research results and finds that there are relatively few research results on the typical bad soft soil in Qinghai Lake Basin, and the theoretical research on the influence of water content change and drying-wetting cycle on the "water meadow" is insufficient.

Figure 1 shows the location of the section requiring foundation reinforcement. The main surface water system along the reinforcement area of the project is Chahannuo River, which is a plateau river. The river flows generally from north to south, and the highest flood season is from midJune to September every year. Moreover, the river is mainly supplied with a rainstorm and melting water for the snowcapped mountains, which hold the typical characteristics of the sudden rise and fall of rivers in upper mountainous areas. In addition, the reinforcement area of the project is situated in the triangle zone, lying low, which is conducive to the collection of surface water. Regional areas have accumulated water all the year-round, forming a large area of swamp, showing "water meadow."

The bedrock soil of the "water meadow" in the project reinforcement area is predominantly silt, pebble soil, and weathered granodiorite, which have been flooded for a long time with abundant groundwater. The exposed thickness of the soft soil layer of surface turf is $1 \sim 3 \mathrm{~m}$. The silty soil layer is $3 \sim 8 \mathrm{~m}$ thick and distributed in the lower part of the soft soil of turf. It is brownish gray, soft plastic, and wet-saturated, with high density, and the main components are clay and silt, and bedding characteristics are not obvious. The pebble layer is gray and bluish-gray, with a large density and wet-saturated state. Particle composition: $5 \%$ of particles larger than $20 \mathrm{~mm}$, 45 to $50 \%$ of particles between 2 and $20 \mathrm{~mm}$, and 35 to $45 \%$ of particles between 0.075 and $2 \mathrm{~mm}$. The rest is filled with powder clay. In addition, particles are round and subround, with a maximum diameter of $30 \mathrm{~mm}$ and a general diameter of $2-15 \mathrm{~mm}$. They are mainly composed of sandstone and granite, with inferior grain gradation.

\section{Study on the Influence of Water Content on the Shear Strength of Silt}

3.1. Experiment Information. Combined with engineering investigation data, the influence of groundwater on the silt in the water meadow was studied by the geotechnical test and the direct shear test. According to the engineering survey data, the water content of the silt layer in the field is between $15 \%$ and $30 \%$ during the survey period, and the survey work is performed in the non-main flood season.

The undisturbed soil was soaked in water on-site to simulate the change of soil moisture content after the "water meadow" rose in flood season, and the soil was not changed except by adding water. After soaking the soil to different states, use a ring knife to sample and make multiple groups of soil samples with distinct dry and wet degrees under the same conditions. Prepare at least 4 groups (3/group) of soil samples with the same dry and wet degrees, of which 2 groups measure the water content of soil samples by geotechnical test and 2 groups measure the shear strength index of soil samples by direct shear test. The test process is shown in Figures 2 and 3.

3.2. Test Data Analysis. The relationship between shear strength indexes and water content of soil samples in each group is plotted as shown in Figures 4 and 5 . When the principal stress $\sigma$ is $100 \mathrm{kPa}$ and $200 \mathrm{kPa}$, the relationship between shear strength and water content of the soil is plotted as shown in Figures 6 and 7.

Figure 4 shows that the relationship curve between cohesion $c$ and moisture $w$ content of soil samples does not vary regularly. When the water content is in the range of $20 \%-45 \%$, cohesion is divided into two parts by the water content. When the water content $w \leq 20 \%-45 \%$, the cohesion increases linearly with the increase of water content, and the increase is large; when the water content $w \geq 20 \%-$ $45 \%$, cohesion decreases with the increase of water content, but the decrease is not significant. Hence, according to the above analysis rule, the discrete sample data are eliminated; when the water content is in the range of $20 \%-45 \%$, the maximum value of cohesion $c$ is about $26 \mathrm{kPa}$, and the corresponding optimal water content is about $32 \%-34 \%$.

Figure 5 shows that the relationship between the internal friction angle $\varphi$ and the water content of soil samples shows a trend of increasing or decreasing first. The relationship between the internal friction angle $\varphi$ and water content has two peaks between $20 \%$ and $45 \%$; the first is at $w=30 \%-31 \%$ and the second is in $w=37 \%-39 \%$. However, when the water content $w \leq 30 \%-31 \%$, the internal friction angle increases with the increase of water content, which is approximately linear. When $30 \% \leq w \leq 37 \%$, with the increase of water content, the internal friction angle decreases at first and then increases slightly. When $w \geq 39 \%$, the internal friction angle declines with the 


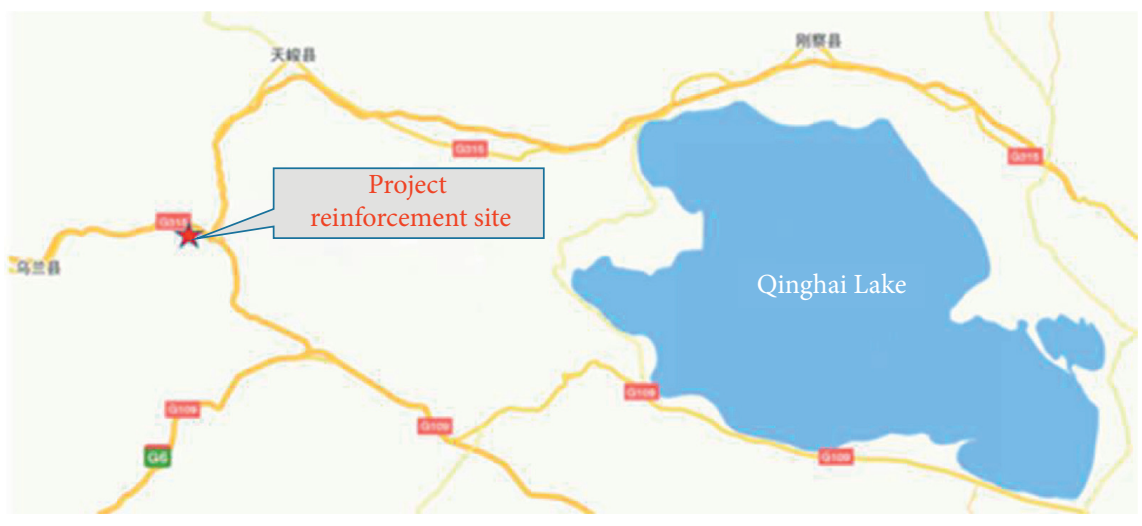

Figure 1: Project reinforcement site.

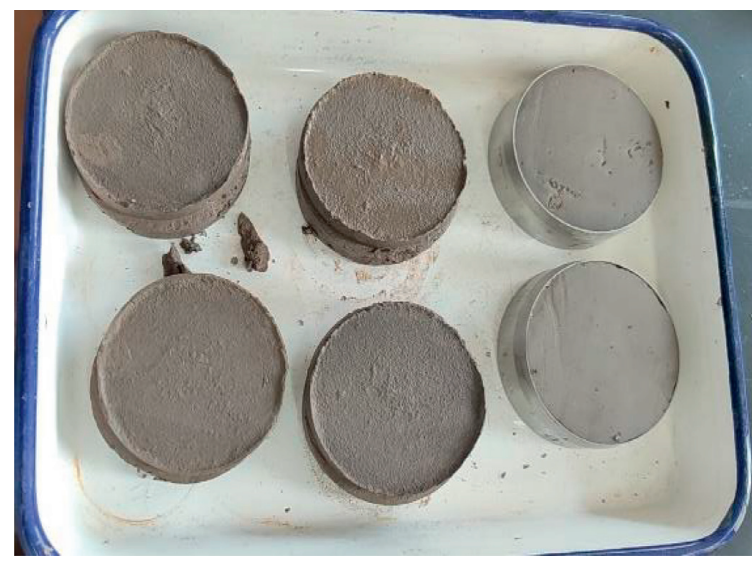

Figure 2: Preparation of soil sample.

increase of water content. When $20 \% \leq w \leq 45 \%$, the maximum value of the internal friction angle $\varphi$ is about $27^{\circ}$; at the same time, the optimal moisture content is about $30 \%-31 \%$.

Figures 6 and 7 show that when the principal stress is $100 \mathrm{kPa}$ and $200 \mathrm{kPa}$, respectively, the relationship between the shear strength and water content of silt is basically consistent with the changing trend of the internal friction angle. The two peaks of the curve are at $w=30 \%-31 \%$ and $w=37 \%-39 \%$, respectively. When the moisture content $w$ $\leq 30 \%-31 \%$, the shear strength of soil increases with the increase of water content. When $30 \% \leq w \leq 37 \%$, with the increase of water content, the shear strength decreases at first and then increases slightly. When $w \geq 39 \%$, the shear strength declines with the increase of water content. When $20 \% \leq w \leq 45 \%$, the optimal moisture content is about $30 \%-31 \%$.

According to the above test data and analysis results, when the water meadow is strengthened, the shear strength indexes can be improved by monitoring the moisture content of the soil. When the moisture content is checked at about $30 \%$, the silt soil can obtain relatively good shear strength. In addition, since the moisture content has a great influence on the shear strength index of silt soil, the deterioration of soil mechanical indexes should be considered in engineering design and calculation of the long-term deformation of the water meadow.

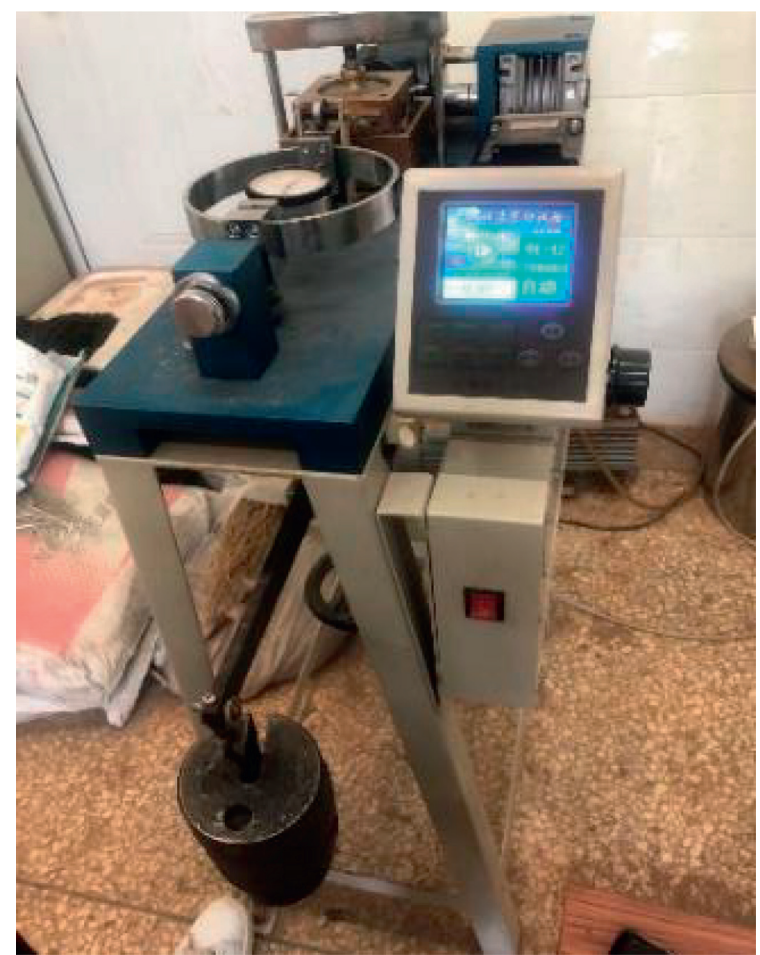

Figure 3: Direct shear test.

\section{Study on the Influence of Dry-Wet Cycle on the Shear Strength of Silt}

4.1. Experiment Information. To simulate the drying-wetting cycle state of silt of aquatic grass soil caused by seasonal changes and ensure the uniformity of soil samples, the soil system was made into remolded soil. After mashing and grinding the soil, water was added, and then the remolding process was carried out after mixing evenly, as shown in Figures 8 and 9 . The remolded soil was processed by dry-wet cycles 1 7 times, and dry soil and wet soil samples were made in each cycle, In addition, the moisture content of dry soil samples was controlled at 25\% 28\% and wet soil samples was controlled at $44 \% \sim 46 \%$, respectively. Then, the soil samples of 1, 2, 3, 5, and 7 times of dry-wet cycles were subjected to geotechnical tests and direct shear tests, and the 


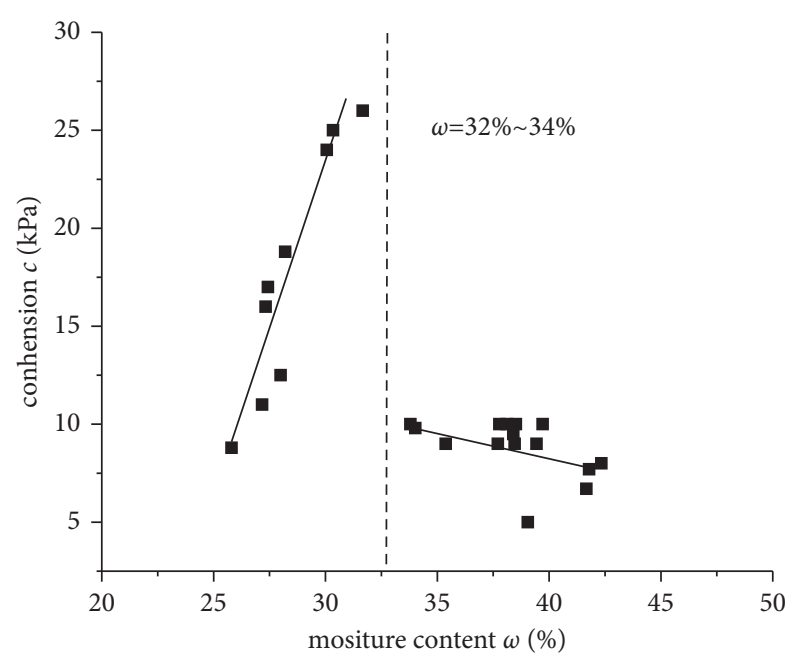

Figure 4: $c-w$ curve.

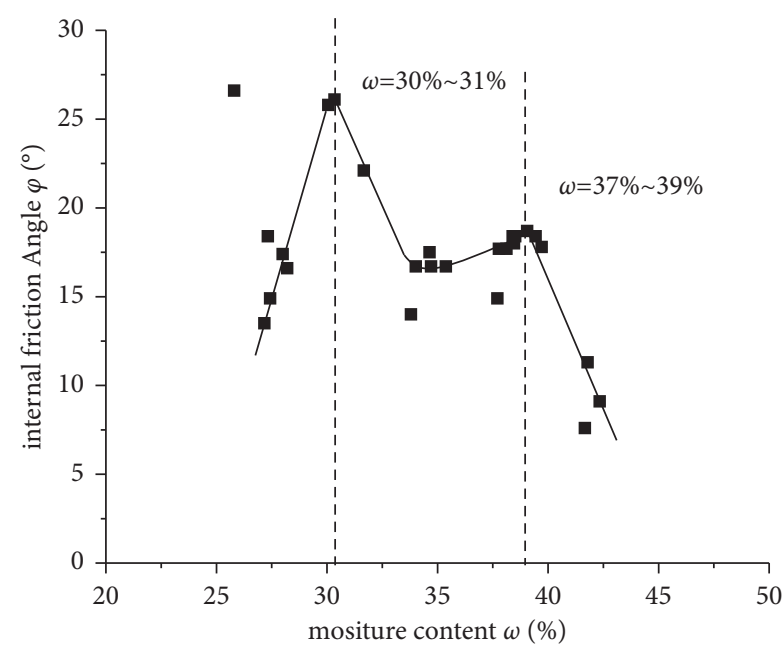

Figure 5: $\varphi-w$ curve.

test humidity of soil samples with the condition of not less than 2 groups (3 / group).

4.2. TestData Analysis. Plot the soil shear strength indexes of each cycle number, as shown in Figures 10 and 11.

Figure 10 shows that $c$ of silt layer in water meadow decreases with the increase of the number of drying-wetting cycles, and the decrease is greater in the first three cycles. However, after three cycles, the cohesive force remains basically unchanged. The cohesion of dry soil (water content in $25 \%-28 \%$ ) in the initial state is much higher than that of wet soil (water content in $44 \%-46 \%$ ), which is approximately $16 \mathrm{kPa}$ and $8.5 \mathrm{kPa}$, respectively. The cohesion of dry soil in the first two cycles is greater than that of wet soil. After the third cycle, the cohesion of dry soil and wet soil was approximately $5.7 \mathrm{kPa}$ and $5.0 \mathrm{kPa}$, respectively, which is relatively close. After the seventh cycle, the cohesion of dry soil and wet soil is approximately $4.0 \mathrm{kPa}$, and there is basically no difference in the cohesion of dry soil and wet soil.

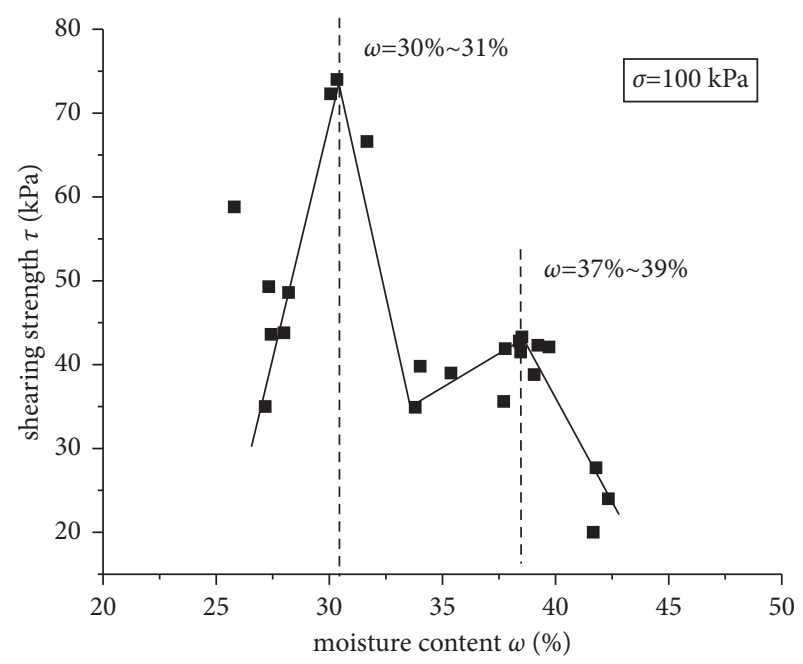

Figure 6: $\tau-(w)$ curve $(\sigma=100 \mathrm{kPa})$.

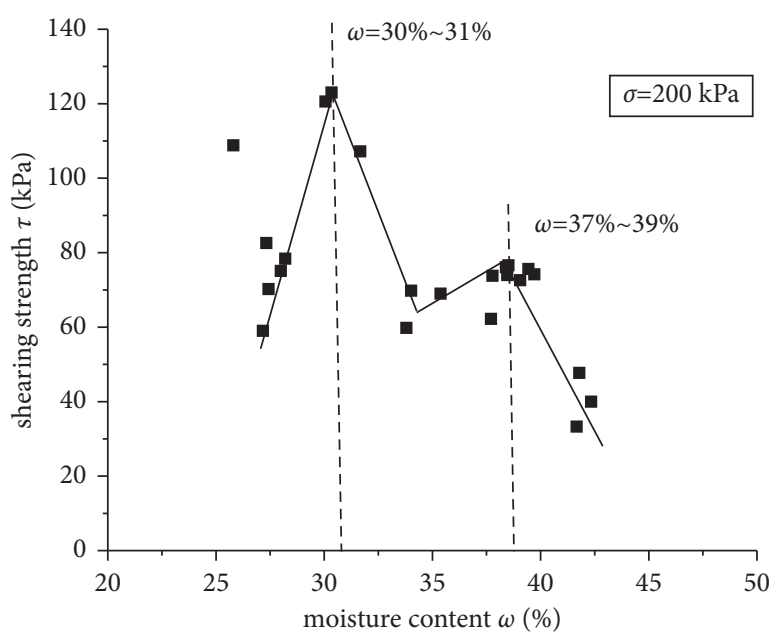

Figure 7: $\tau-(w)$ curve $(\sigma=200 \mathrm{kPa})$.

Figure 11 shows that the internal friction angle $\varphi$ of silt layer in water meadow decreases with the increase of the number of wet and dry cycles, and the internal friction angle value fluctuates slightly in the first two cycles, which decreases first and then increases. After two cycles, the internal friction angle decreases approximately linearly with the number of cycles. For the first three cycles, the internal friction angle of dry soil (water content between 25\% and $28 \%$ ) was larger than that of wet soil (water content between $44 \%$ and $46 \%$ ), the internal friction angle of dry soil and wet soil at the initial stage was approximately $23^{\circ}$ and $16.8^{\circ}$, respectively, and the maximum internal friction angle (the second cycles) of dry soil and wet-dry is about $24^{\circ}$ and $20.7^{\circ}$, respectively. After five drying-wetting cycles, the internal friction angle of dry soil and wet soil is about $15.5^{\circ}$ and $15^{\circ}$, respectively, which is close to each other. When the cycle reaches 7 times, the internal friction angle of dry soil and wet soil is about $11.2^{\circ}$, and there is almost no difference in cohesion between dry soil and wet soil.

The principal stress is divided into $100 \mathrm{kPa}, 200 \mathrm{kPa}$ and $300 \mathrm{kPa}$, and the change line diagram of shear strength of dry 


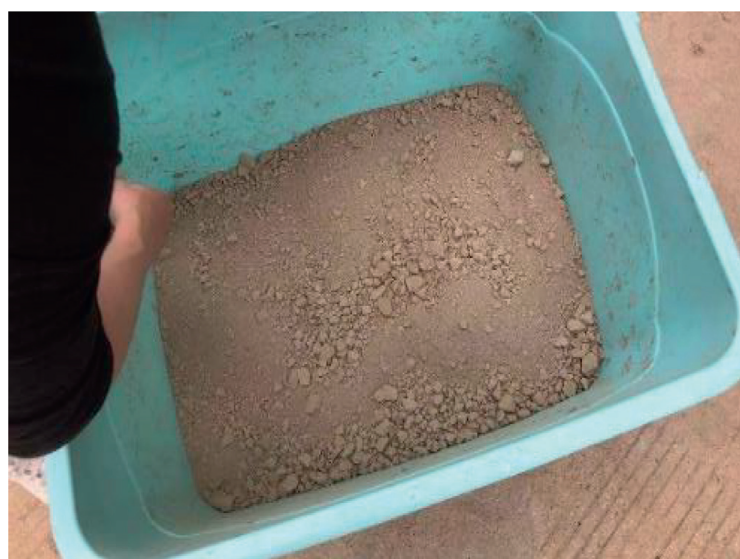

FIGURE 8: Making granular remolded soil.

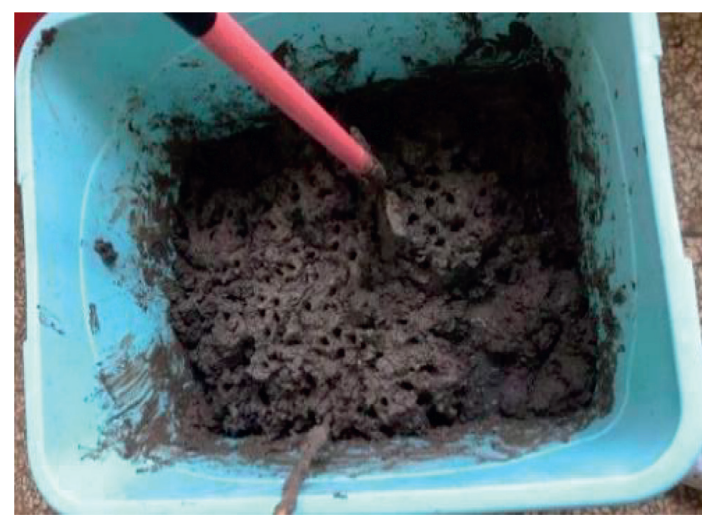

FIGURE 9: Remodeling soil after adding water.

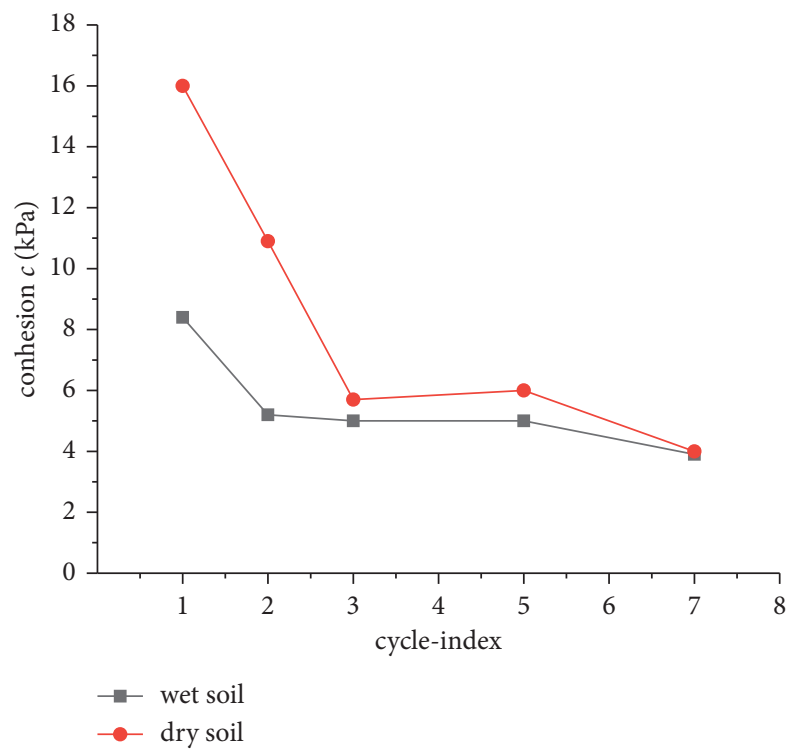

FIGURE 10: $c$-drying-wetting cycle curve.

soil and wet soil under different cycle times and corresponding dry-wet cycle time is drawn, as shown in Figure 12.

Figure 12 shows that the shear strength of the silt layer of the water meadow under various principal stress states reaches the maximum value in the second cycle and then

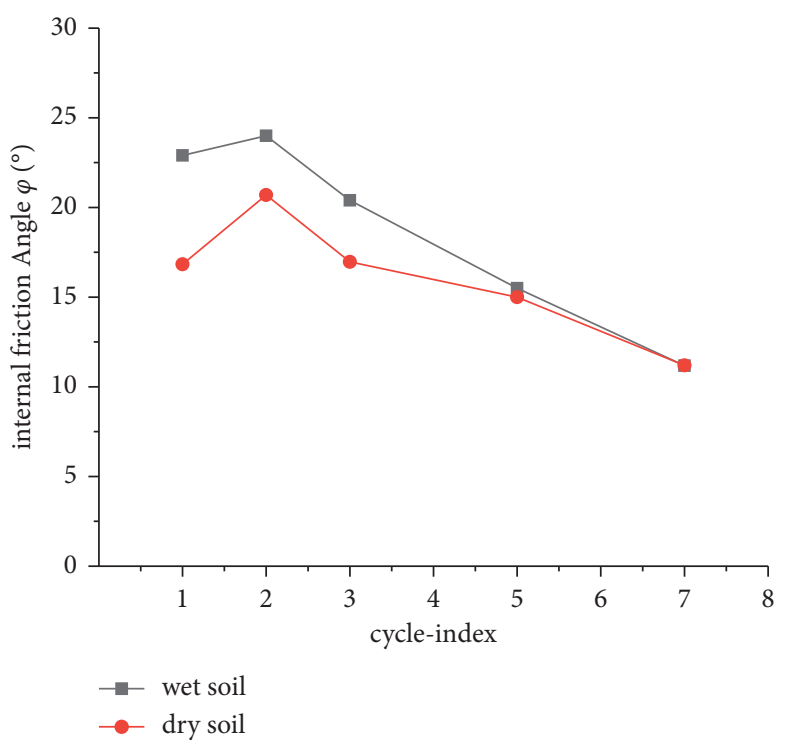

FIgURE 11: $\varphi$-drying-wetting cycle curve.

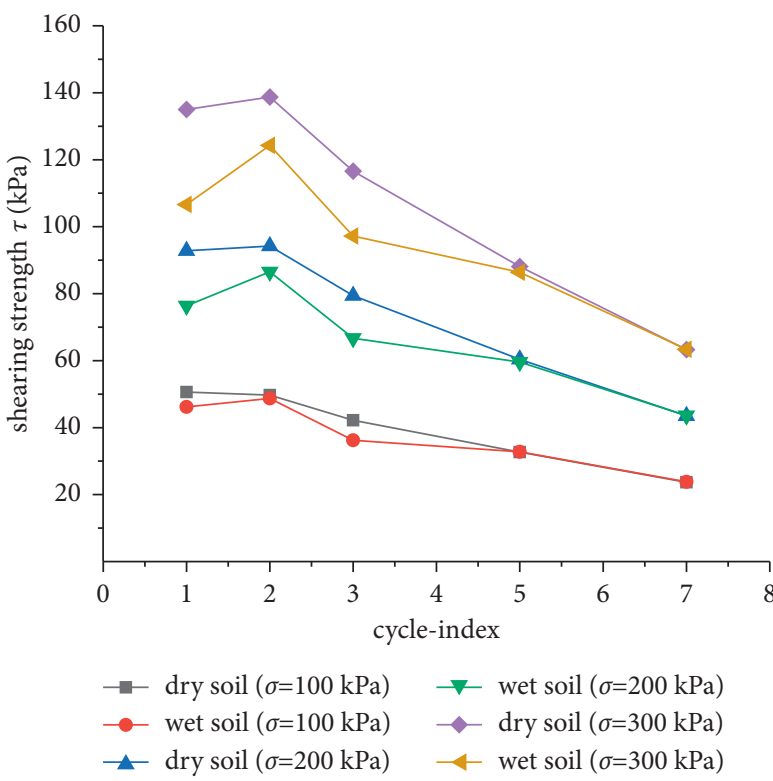

FIGURE 12: $\tau$-drying-wetting cycle curves.

decreases gradually with the increase of the number of drying-wetting cycles. In the first three cycles, the shear strength of dry soil is always higher than that of wet soil. In addition, with the increase of principal stress, the shear strength of dry soil is greater than that of wet soil. In the initial state, when the principal stresses are $100 \mathrm{kPa}, 200 \mathrm{kPa}$, and $300 \mathrm{kPa}$, respectively, the shear strength of dry soil is 1.1 times, 1.21 times, and 1.27 times that of wet soil. When the cycle reaches 3 times, the shear strength ratio of dry soil and wet soil is 1.17 times, 1.19 times, and 1.2 times. When the cycle reaches 5 times, the shear strength ratio of dry soil and wet soil is approximately the same, and there is no difference between dry soil and wet soil.

According to the above analysis, the drying-wetting cycles have a significant influence on the shear strength and 
indexes of silty soil of water meadow and the drying-wetting cycles will cause the deterioration of the cohesion and internal friction angle of a silty soil. However, when the cycle is more than 5 times, the shear strength and indexes of dry and wet soil are approximately the same, and there is no difference between dry soil and wet soil. The experiment shows that in engineering practice, the method of reducing drainage for the first time can enhance the strength of the soil. However, after many times of "reducing drainagehardening-water storage-infiltration," the water content of the soil is still reduced, and the strength of soil is not significantly improved.

\section{Conclusion}

The present study investigated the influence of moisture content and drying-wetting cycles on the shear strength indexes of the silt in the west bank of Qinghai Lake, and the key findings of this study can be synthesized as follows:

(1) By measuring the shear strength index of silt samples with different water contents, it is found that when the water content of silt is $w \leq 32 \%-34 \%$, the soil cohesion increases with the increase of water content. Meanwhile, when $w \geq 32 \%-34 \%$, the cohesion decreases with the increase of water content. Moreover, the relationship between internal friction angle and water content of silt increases firstly and then decreases. However, when $w$ $\leq 32 \%-34 \%$, the internal friction angle increases with the increase of water content. However, when $32 \% \leq w \leq 34 \%$, the internal friction angle decreases first and then increases slightly with the increase of water content. However, when $w \geq 39 \%$, the internal friction angle declines with the increase of water content. However, when the moisture content is located in the range of $20 \%-45 \%$, the optimal moisture content corresponding to the cohesion is about $32 \%-34 \%$. In addition, the optimal moisture content corresponding to the internal friction angle and the shear strength is about $30 \%-31 \%$.

(2) Through the drying-wetting cycle processing and direct shear test of silt remolded soil, the test results show that the drying-wetting cycles have a great influence on the shear strength and indexes of silt soil of water meadow, and the cohesion, internal friction angle, and shear strength of silt will gradually decrease or tend to be stable with the increase of the number of drying-wetting cycles. However, in the first three cycles, the shear strength index of dry soil is larger than that of wet soil. In addition, when the cycle is more than 5 times, the soil moisture content has no effect on the shear strength index, and the indexes of dry and wet soil are approximately the same.

(3) When the aquatic grass land is in the state of longterm water accumulation, the shear strength of the silty soil layer of the water meadow can be improved by monitoring the moisture content of the soil.
Moreover, the moisture content of the soil can be controlled at about $30 \%$, and the silty soil layer can obtain relatively good shear strength. However, when calculating the long-term strength and deformation of soil, it is necessary to consider the influence of water content change in the deterioration of shear strength indexes.

(4) When the water meadow is in the state of dryingwetting circulation for a long time, reducing the soil water content by lowering the drainage method may not play a role in improving the shear strength of the soil or the effect is not obvious.

\section{Data Availability}

The data used to support the findings of this study are included within the article.

\section{Conflicts of Interest}

The authors declare that they have no conflicts of interest.

\section{Acknowledgments}

This study was supported by Provincial and Ministerial Funds of China (2021-SF-168).

\section{References}

[1] L. Peng, S. Zhao, A. Li, and M. H. Li, "Influence of water seepage softening of slope soil on slope stability," Engineering Investigation, no. 1, pp. 26-28, 2002.

[2] L. A. M. Raymond and R. Huang, "Triaxial test study on water sensitivity of sliding zone soil strength," Chinese Journal of Engineering Geology, vol. 12, pp. 112-117, 2004.

[3] L. Hua and Z. Yin, "Variation of unsaturated soil strength with water content," Journal of Rock Mechanics and Engineering, vol. 26, no. 7, pp. 1499-1503, 2007.

[4] L. Hua, Z. Yin, and Z. Cai, "Experimental study on stressmoisture-strain relationship of unsaturated soil," Rock and Soil Mechanics, vol. 29, no. 3, pp. 651-655, 2008.

[5] Y. Zhou, W. Zuo'an, S. Zhu, and Q. G. Zhang, "Influence of thickness and water content of sliding zone soil on its strength parameters," Chinese Journal of Geological hazard and Control, vol. 21, no. 6, pp. 25-29, 2010.

[6] J. Li, Q. Yang, and C. Meng, "Relationship between unsaturated shear strength index C and water content W," Geotechnical Engineering Technology, vol. 24, no. 5, pp. 243-247, 2010.

[7] B. Huang, X. D. Fu, F. Tan, and Z. M. Wu, "Experimental study on the influence of water content on the strength and deformation of sliding zone soil," Rock and Soil Mechanics, vol. 33, no. 9, pp. 2613-2618, 2012.

[8] P. Liu, C. Liu, L. M. Kang, and L. L. Ji, "The experiment and research of yunnan laterite's shear strength under function of dry-wet cycle," in Proceedings of the 2018 2nd International Workshop on Renewable Energy and Development (IWRED 2018), pp. 1-7, Guilin, China, April 2018.

[9] S. C. Tang, J.-J. Wang, Z.-F. Qiu, and Y.-M. Tan, "Effects of wet-dry cycle on the shear strength of a sandstone-mudstone particle mixture," International Journal of Civil Engineering, vol. 17, p. 2, 2018. 
[10] J. Du, K. Yin, and S. Lacasse, "Displacement prediction in colluvial landslides, three Gorges reservoir, China," Landslides, vol. 10, no. 2, pp. 203-218, 2013.

[11] H. F. Deng, J. L. Li, M. Zhu, K.-W. Wang, L.-H. Wang, and C.-J. Deng, "Experimental study on strength deterioration of sandstone under the cyclic action of saturated water and air drying," Rock and Soil Mechanics, vol. 33, no. 11, pp. 483-488, 2012.

[12] H. F. Deng, J. L. Li, K.-W. Wang, H.-B. Zhang, and C.-X.-J. Wang, "Study on the change law of secondary porosity of sandstone during saturated-air-dried cycle," Rock and Soil Mechanics, vol. 33, no. 2, pp. 3306-3312, 2012.

[13] H. F. Deng and J. C. Fang, "Study on the degradation law of soil shear strength in the fluctuating zone of bank slope under the action of dry-wet cycle and its influence on the stability of bank slope," Rock and Soil Mechanics, vol. 38, no. 9, pp. 2629-2638, 2017.

[14] X. Liu, L. Zhang, and Y. Fu, "Experimental study on the influence of wet and dry cycles in acidic environment on the mechanical properties of argillaceous sandstone," Rock and Soil Mechanics, vol. 35, no. S2, pp. 45-52, 2014.

[15] Q. Jiang, L. Liu, Y. Jiao, and H. Wang, "Experimental study on strength characteristics and microstructure of soil in sliding zone under dry-wet cycle," Rock and Soil Mechanics, vol. 40, no. 3, pp. 1005-1012, 2019.

[16] B. Wu, G. Xu, and W. Liu, "Study on disintegration and strength weakening characteristics of red mudstone in Badong formation of three Gorges reservoir area," Safety and Environmental Engineering, vol. 27, no. 2, pp. 50-57, 2020.

[17] Y. Yao, J. Ni, and J. Li, "Stress-dependent water retention of granite residual soil and its implications for ground settlement," Computers and Geotechnics, vol. 129, Article ID 103835, 2021.

[18] J. Zhang, A. Zhang, C. Huang, H. Yu, and C. Zhou, "Characterising the resilient behaviour of pavement subgrade with construction and demolition waste under Freeze-Thaw cycles," Journal of Cleaner Production, vol. 300, Article ID 126702, 2021.

[19] J. Zhang, F. Li, L. Zeng, J. Peng, and J. Li, "Numerical simulation of the moisture migration of unsaturated clay embankments in southern China considering stress state," Bulletin of Engineering Geology and the Environment, vol. 80, no. 1, pp. 11-24, 2020

[20] J. Zhang, J. Peng, A. Zhang, and J. Li, "Prediction of permanent deformation for subgrade soils under traffic loading in Southern China," International Journal of Pavement Engineering, vol. 21, pp. 1-10, 2020. 